Thus,

$\frac{\lambda_{y}}{\lambda_{\beta}}=\frac{3 \cdot 37}{27 \cdot 4}=0.123 \pm 0.003$ ( \pm probable error $)$.

Mousuf ${ }^{11}$ measured the ratio argon-40 to potassium40 for geological samples (assumed to be $1.03 \times 10^{9}$ yr. old), and on the basis of a total half-life for potassium-40 of $1.27 \times 10^{9} \mathrm{yr}$. obtained $\frac{\lambda\left({ }^{40} \mathrm{~K} \rightarrow{ }^{40} \mathrm{~A}\right)}{\lambda\left({ }^{40} \mathrm{~K} \rightarrow{ }^{40} \mathrm{Ca}\right)}$ $=0.053-0.066$. There is thus a discrepancy amounting to a factor of 2 (at least) between this conclusion and that derived from the most reliable radioactivity data. It would seem likely that either the age of the samples has been over-estimated or argon-40 may have diffused out of them.

Half-life of potassium-40. If we regard all transitions of potassium-40 to argon-40 as being accompanied by the emission of a 1.46-MeV. quantum, we may assign an upper limit to the half-life of potassium-40. Nier ${ }^{12}$ found the relative isotopic abundance of potassium-40 in ordinary potassium to be $(0.0119$ t $0.0001)$ per cent; using the values for the specific $\beta$ - and $\gamma$-activities quoted above, we find $T_{1 / 2} \leqslant$ $\left(1 \cdot 31_{\mathrm{s}} \pm 0 \cdot 04\right) \times 10^{\circ} \mathrm{yr}$.

This work was carried out as part of an investigation of the radioactivity of the human body, and was supported by the Medical Research Council.

Note added in proof. In the light of recent experimental work (Valentine, J. M., Proc. Roy. Soc., A, $211,75 ; 1952)$ and other less direct evidence, the author is of the opinion that the currently accepted value for $W$ (see above) of $32.5 \mathrm{eV}$. may be appreciably in error and that the true value for fast electrons may be as high as $35 \cdot 0 \pm 0 \cdot 5 \mathrm{eV}$. If this latter figure should be substantiated, the above conclusions would need to be revised as follows:

Specific $\gamma$-activity of ordinary potassium (this research) $=3.63 \pm 0.10$ quanta sec.-1 $\mathrm{gm}^{-1}$. Weighted mean of this and other determinations $=$ $3 \cdot 48 \pm 0.08$ quanta sec..$^{-1} \mathrm{gm}^{-1}$. Branching ratio $=$ $0 \cdot 127 \pm 0.003$. Half-life of potassium $40 \leqslant(1 \cdot 31 \pm$ $0.04) \times 10^{\circ} \mathrm{yr}$.

Department of Medical Physics,

$$
\text { P. R. J. BURCH }
$$

University of Leeds.

April 21.

${ }^{2}$ Halpern, $O_{\text {, }}$ and Hall, H., Phys. Rev., 73, 477 (1948). Sternheimer, R. M., Phys. Rev., 88, 851 (1952).

2 Taylor, L. S., and Singer, G., Amer. J. Roentgenol., 44, 428 (1940).

${ }^{3}$ Bell, P. R., and Cassidy, J. M., Phys. Rev., 79, 173 (1950). Good, M. I.., Phys. Rev., 81, 891 (1951).

- Evans, R. D., and Evans, R. O., Rev. Mod. Phys., 20, 305 (1948).

sawyer, G. A., Weidenbeck, M. I.., Phys. Rev., 79, 490 (1950).

- Spiers, F. W., Nature, 165, 356 (1950).

' Faust, Phys. Rev., 78, 624 (1950).

${ }^{8}$ Gráf, T., Rev. Sci. Instr., 21 (1950).

- Paganelli, M., and Quareni, G., Phys. Rev., 86, 423 (1952). Johnson, W. H., Phys. Rev., 88, 1213 (1952).

${ }^{10}$ Gráf, T., Phys. Rev., 74, 831 (1948). Good, M. I., Phys. Rev., 83,

${ }^{11}$ Mousuf, A. K., Phys. Rev., 87, 150 (1952).

${ }^{12}$ Nier, A. O., Phys. Rev., ' '7\%, 789 (1950).

\section{Szilard and Chalmers Effect by Irradiation of Hexavalent Chromium in an Atomic Pile}

MUXarT et al. ${ }^{1}$ found that no rapid exchange of chromium takes place between hexavalent and trivalent chromium in solution. This has later been verified by Menker and Garner ${ }^{2}$. Muxart et al. used this result for investigating a possible SzilardChalmers effect in dichromate irradiated by slow neutrons, and found that if an effect does exist in this case it is extremely weak.

Burgus and Kennedy ${ }^{3}$ investigated the chemical effects accompanying the decay of manganese-51, which is transformed to chromium-51, and found that the amounts of trivalent and hexavalent chromium produced to a large extent depended on the chemical milieu. Since certain tracer experiments with chromium-51, made by irradiation of solid $\mathrm{CrO}_{3}$ in a heavy water/uranium pile, indicated that tracer amounts of trivalent chromium were present, it was assumed that sirnilar phenomena, as in the case of the decay of manganese-51, might take place by the irradiation of hexavalent chromium.

Solid $\mathrm{CrO}_{3}, 6 \mathrm{M}$ chromic acid, and solid $\mathrm{KCrC}_{4}$ and $\mathrm{K}_{2} \mathrm{Cr}_{2} \mathrm{O}_{3}$ were irradiated in the pile, and the activity of trivalent and hexavalent chromium determined with the following result:

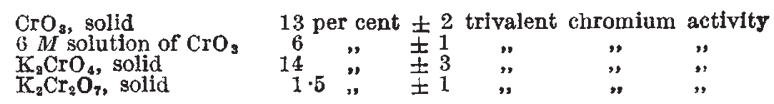

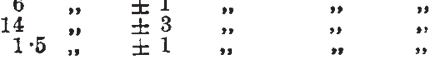

The limits given for the percentage activity of trivalent chromium are estimated from the deviations of single experiments.

To make sure that the trivalent chromium activity was really due to chromium-51, the decay and the absorption in aluminium of the radiation from the trivalent and hexavalent chromium specimens were compared and found to be identical. The specimens also followed the chemical reactions of chromium.

A more detailed account of the investigations will be given elsewhere.

Norwegian Defence Research Establishment,

Chemical and Metallurgical Division,

Lillestıøm, Norway.

May 13.

${ }^{1}$ Muxart, R., Daudel, O., Daudel, R., and Haissinsky, M., Nature, 159,538, (1947).

Menker, H. E., and Garner, C. S., J. Amer. Chem. Soc., 71, 371 (1949).

${ }^{3}$ Burgus, W. H., and Kennedy, J. W., J. Chem. Phys., 18. 97 (1950).

\section{Dependence of Glow to Arc Transitions on Cathode Surface Conditions}

EARLIER workers have shown that the relative stability of glow and arc discharges on both refractory and non-refractory electrodes is seriously affected by cathode conditions such as oxide layers ${ }^{1}$, vapour clouds $^{2}$, salt contaminations ${ }^{3}$ and temperature ${ }^{4}$. However, owing to the rapid destruction by the discharge of prepared cathode surfaces, it has not been possible in the past to determine in a positive manner the effects of cathode surface condition on the glow to are transition process.

A technique has now been developed, however, in which a glow discharge is moved electromagnetically between two parallel rod electrodes and is thus brought on to a part of the cathode having a specially prepared surface. Observation then shows whether the change in surface condition produces a glow to arc transition. For example, with clean tungsten electrodes in free air the conditions are set so that the glow discharge may be moved along the full length of the electrodes any number of times without transitions taking place. By simply placing a few grains of common salt at one point of the cathode 